\section{D.D.T. AND THE AEROPLANE IN THE CONTROL OF THE TSETSE FLY AND TRYPANOSOMIASIS IN SOUTH AFRICA}

A MEETING was held on September 24 at the A London School of Hygiene and Tropical Medicine to see a film and hear an address by Dr. P. J. du Toit, director of Veterinary Services, Union of South Africa, on a tsetse fly control experiment that has recently been completed in Zululand, where some 1,000 square miles of country are infested by the fly, with adjacent areas amounting to a further 6,000 square miles subject to infestation. The meeting was arranged by the Imperial Bureau of Animal Health and other bodies and was attended by an audience of more than three hundred and fifty, representative of the many interests concerned in the campaign against this scourge of Africa.

Mr. Heaton Nicholls, High Commissioner of South Africa, spoke of the advantages to be gained in Africa if this pest could be eliminated. He said that he had personal experience of the losses caused by its prevalence; as a parliamentarian, Zululand had been within his range of interests and caused him a good deal of trouble. He gave a graphic description of the tragedy that followed an attempt by settlers to develop farms in 'fly' areas of Zululand after the First World War. Their cattle died from 'nagana' (trypanosomiasis) and many had to leave their farms, numbers of them becoming bankrupt.

It is to be remembered that, apart from a small area at the tip of Southern Arabia, where one species of Glossina is said to occur, the flies of this genus exist only in Africa. These flies feed only on blood, chiefly on that of warm-blooded animals. The female hatches a single larva at a time; this remains in the uterus until the pupa is nearly mature, when it is deposited on the ground. The larva burrows into the soil and pupates within a very short time. From that stage the adult develops as do other muscids. The habits of the adult are highly specialized, and within the score or so of species there is considerable variation in the requirements for development and for propagating the species. Some species require a high degree of shade and humidity; some are confined in their distribution to river banks and streams. Others require dense shade and are limited to forests; again, others prefer more open park land. Some can feed on cold-blooded animals. Some are homophilic, others are zoophilic. Some require access to large game animals, such as buffalo, koodoo, etc.; others can maintain themselves on small game animals, such as the warthog, bushbuck, etc. The flies acquire their infection with pathogenic trypanosomes when they feed on the game animals; the game are immune, but the domestic animals are highly susceptible to infection.

Difficult as it is to achieve success in the control of the tsetse fly by deliberately undertaken artificial measures, there is considerable experience of its disappearance from areas previously very seriously affected. At one time Glossina morsitans was prevalent in the Transvaal, but it disappeared at about the time of the great rinderpest epizootic of the eighteen-nineties. At that time the game animals were depleted by hunting, and many of them suffered severe losses along with the cattle from the rinder. pest ; thus the hosts of the fly became scarce. It is significant that it has not reappeared in the Transvaal. Similarly, the fly has disappeared from other areas where it had been prevalent. Such instances are, however, limited. These experiences give hope that, in suitable circumstances, properly executed control measures, based on sound principles, might yield more than temporary success.

Intensive study of the flies has been undertaken in Zululand for many years, and a large amount of information has been acquired concerning their distribution and relative density in the different types of vegetation and land and soil formation. The conditions, beneficial and adverse, to the existence of the flies are now well understood.

Some success in eliminating the fly has been attained by selective clearing of bush in such a way that the shade required by the fly is removed. The manner in which the clearing is done depends upon the species of fly concerned; when carried out by trained personnel the clearing is done so selectively that a minimum of labour is required. Many of those concerned in dealing with this problem consider that, although the cost is high, it is the most practicable method of control.

By the elimination of the wild game animals, the main source of the insect's food supply is removed. This question of the game animals is highly controversial. Those with farms in the affected areas and many concerned in developing ' $\mathrm{fly}$ ' areas urge that the game should be removed. On the other hand, there is very strong opposition to such a policy.

An area in Zululand was selected for a large-scale attempt to control the fly, the one concerned being G. pallidipes, a zoophilic savannah species. An attempt was made to effect a useful measure of control by the use of the well-known ingenious Harris fly trap. Very large numbers of the flies were collected and killed by this means; but it was found that there was no possibility of exterminating them. The traps do, however, provide a most accurate means for assessing the 'fly' population of an area and are, consequently, a most important tool for correlating the results of attempts at control by any other method.

In the use of the D.D.T. on the ground the spacing of the successive treatments was planned in order to ensure that the pupæe present on the first occasion would have hatched before the final one was given. Hand-spraying with D.D.T. was carried out, but was found to be unsuitable, because when the spray was delivered in this manner from the ground there was not sufficient penetration of the foliage ; in addition, the application took so long to complete and such a large personnel was required that the method was also impracticable for these reasons.

The use of the aeroplane was then considered. The experience acquired in some parts of the world, during and since the Second World War, in the use of aircraft for distributing parasiticides for the control of mosquitoes and also of flies concerned in the spread of dysentery in troops on active service, had indicated the extent to which this method would be useful. The South African Air Force co-operated and supplied pilots, the aircraft and also the necessary service. After preliminary tests, a system was devised whereby tanks carrying the D.D.T. preparation discharged into the exhaust system of the twin-engined Anson aircraft used, so that the exhaust gases gave good sublimation of active D.D.T. in the form of a dense white smoke. 
Flying across wind at 120 m.p.h. at a height of about $50 \mathrm{ft}$., with wind speeds of 6-10 m.p.h., an effective swathe width of 70 yards was obtained, approximately 50 acres per minute being sprayed. The cost of dressing about 100 square miles was $2 s$. an acre for the D.D.T. and 1s. per acre for the aircraft services. Six dressings were given, so the total cost was 18s. an acre. Up to six aircraft were used at a time, succeeding ones following the leader at intervals and taking alignment at the edge of the visible spray left by the one in front. Flying so close to the ground involves some definite risk of accident, and to meet this point it is suggested that a height of $75 \mathrm{ft}$. might be used without materially affecting the lie of the D.D.T.

Elaborate tests were made of the actual spread of the D.D.T. in the bush country used for the experiment. Where there were breaks in the ground because of small ravines, the spread was uneven, and D.D.T. grenades placed by hand were used to supplement the spraying at such places.

Many factors have, of course, to be taken into consideration in assessing the value of the results obtained. So far there has been no indication that there is serious danger that useful forms of life would be permanently exterminated.

The spraying has resulted in a significant drop in the incidence of the tsetse flies in the area treated. The catches in the Harris traps after the spraying were exceedingly low. The flies were not eradicated, but the numbers that survived were small.

This is a pilot experiment, and an enormous amount of work will be required before the relative value of this or any other method of control can be assessed. It has provided certain definite and significant results. Where the fly was a nuisance to individuals working in or passing through the area, they are now rarely noticed. It is considered that with such a considerable reduction in the numbers, the ordinary causes of mortality of the tsetse flyand these are considerable because of the hazards involved in its life-history and of its slow breeding-rate -may lead to its disappearance. On the other hand, the flies may be able again to attain sufficient concentration to menace the health of the livestock.

Sufficient has been done in Africa to justify a tremendously increased scale of operations against the tsetse fly. The amount of money spent on research on methods of controlling the fly since Africa has been developed by the white race has been small indeed-pitifully small-in comparison with the harm it causes and the extent to which it limits the utilization of land potentially valuable for husbandry and other purposes. Here is a problem which requires costly large-scale research. If very large tracts of useful agricultural land could be made available as a result of experimentation, the money would be well spent. It is, of course, to be understood that, hand in hand with successful tsetse fly control in tropical Africa, measures for dealing with prevalent social and agricultural systems that lead to over-stocking and consequent soil erosion would require attention. Not one of the least import ant problems would be the provision of adequate water supplies for livestock and efficient use of such water.

The film showed very clearly the main features of the work done, and Dr. du Toit discussed the many questions involved in consideration of this gigantic problem. South Africa is making a very determined effort to ensure that progress is made, and this pioneer work will serve as a stimulus to those interested in the development of tropical Africa. All concerned are to be congratulated on a piece of work which is a very important landmark in the history of parasite control.

\section{OBSERVATIONS ON THE TRACKS OF SLOW MESONS IN PHOTOGRAPHIC EMULSIONS}

\author{
By C. M. G. LATTES, DR. G. P. S. OCCHIALIN \\ AND \\ DR. C. F. POWELL
}

H. H. Wills Physical Laboratory, University of Bristol

\section{Part 2: Origin of the Slow Mesons}

T $\mathrm{N}$ Part 1 of the present article*, we showed I that two types of mesons exist, and it was suggested that the heavier, $\pi$-mesons, decay to produce the lighter, $\mu$-mesons. In this second part, we discuss the origin of the slow mesons observed in photographic emulsions, and their relation to the mesons forming the penetrating component of the cosmic rays, of which evidence is provided by experiments with Wilson chambers and counters. We also give photomicrographs which show that some slow mesons, ejected from nuclei during 'explosive disintegrations', can enter nuclei and produce a second disintegration. Most of the observations on plates exposed at $5,500 \mathrm{~m}$. were made with boron-loaded emulsions and, for the most part, we have confined our analysis to the results obtained with plates of this type. The loading material has an important influence on the rate of fading of the latent image, but by the above procedure we can compare the results of experiments at different altitudes.

\section{Disintegrations Produced by Mesons}

Of the total of 644 mesons observed to come to the end of their range in our emulsions, 145 give rise to secondary particles. In 40 cases, the track of the secondary particle has characteristics which suggest that it was produced by a meson. We therefore regard these events as due to the decay of $\pi$-mesons although, in several instances, the length of the track of the secondary particle is too short for the identification to be certain. In the remaining 105 cases, the mesons produce disintegrations with the emission of heavy particles. We have previously published photomicrographs of such disintegrations, and Fig. 6 shows an example in which a single proton is ejected. Although we have no evidence that they are all of the same type, it will be convenient to refer, provisionally, to all mesons producing nuclear disintegrations, when moving at low velocity, as $\sigma-m e s o n s$. Since the specifically nuclear interaction between mesons and nucleons may be assumed to be of short range, and since the Coulomb repulsion would tend to prevent a slow positively charged meson from approaching a nucleus, we regard the observation of the disintegrations produced by $\sigma$-mesons as providing strong evidence that they are negatively charged. We show in a later paragraph that there are indications that $\pi$-mesons and some, at least, of the $\sigma$-mesons

* Nature, 160, 453 (Oct. 4, 1947). 